\title{
Practicing Self Learning of ICT for Resilience Amidst the COVID-19 Outbreak: Experiences from Kathmandu Valley
}

\author{
Dhanapati Subedi ${ }^{1} \&$ Ramila Subedi ${ }^{* 1}$
}

* Corresponding author

E-mail: ramilasubedi@kusoed.edu.np

1. Kathmandu University, School of Education, Department of Educational Leadership, Lalitpur, Nepal

\section{Article Info}

Received: October 3, 2020

Revised: December 8, 2020

Accepted: December 9, 2020

\subsection{3/repam.2020.5}

\section{How to cite}

Subedi, D. and Subedi, R. (2020). Practicing Self Learning of ICT for Resilience Amidst the COVID-19 Outbreak: Experiences from Kathmandu Valley. Research in Educational Policy and Management, 2(2), 78-96.

\section{https://doi.org/10.46303/repam.2020.5}

\section{Copyright license}

This is an Open Access article distributed under the terms of the Creative Commons Attribution 4.0 International license (CC BY 4.0).

\begin{abstract}
The purpose of the study was to unravel how the school leaders, teachers, students and parents from Kathmandu Valley have experienced the self- learning of ICT use during the COVID- 19. It basically aimed at exploring how the sudden outbreak of COVID- 19 pandemic led the research participants to different vulnerabilities, and how the adoption of ICT use worked as resilience mechanism for them. Guided by the philosophical assumptions of interpretivism, the study considered the school leaders, teachers, students and parents to have subjective experiences regarding COVID- 19 and ICT use. And for making sense about how they have experienced ICT use amid the pandemic subjectively, narrative inquiry was adopted as research method. Using purposive sampling, a school leader, a teacher, a student and a parent having different socio-economic backgrounds were selected from Kathmandu Valley. Their experiences were assembled through in-depth interview, for which the researchers engaged with them for a prolonged period via phone calls and real time meetings. The assembled experiences were further analyzed with theoretical support, following the process of transcribing, coding, categorization and thematization. Through the collective narratives, it was explored that the COVID- 19 outbreak had come to the research participants, while the adversities they experienced were about the insecurities and stress resulted due to school closures, along with their less familiarity with ICT use. Nonetheless, the adversities were found to have minimized due to their motivation for selflearning of ICT use, and adopting the same, they were found to have grown resilient.

\section{KEYWORDS}

COVID- 19, Coping mechanism, ICT, Resilience, Self- learning.
\end{abstract}




\section{INTRODUCTION}

ICT and its use in academia, for long, has been getting wide coverage in studies. The emphasis reflects very well in M. E.B. (2006 as cited in Cener et.al, 2015) which articulates the shift of Turkish education system towards constructivism with the implementation of ICT integrated projects. Significance of ICT for reinforcing pedagogical approach is illustrated by Ratheeswari (2018) as well who mentions that ICT helps teachers in their role of creating pedagogical environment since they can present teaching more attractively with ICT integration. In the similar context, Waters and Hensely (2020) have highlighted the use of social media as an aspect of ICT, which, with its multimodal functionality and connectivity features, is expected to benefit various school contexts including the ones with limited resources and isolation barriers. Beside the significance that is highlighted, the studies even display a number of challenges to the integration of ICT use, which, as mentioned by Alkahtani (2017) include lack of understanding among pupils and teacher regarding how ICT tools function, lack of mastery in teachers about ICT use and the trainings to bridge the gap. Another challenge is narrated to have been related to the inability of all schools to enjoy the luxury of technology integration since all schools from each nook and corner of a country may not receive equal distribution of devices for making the use of ICT (Waters \& Hensley, 2020).

Coming to the context of Nepal, the use of ICT in education is reviewed to be constantly emphasized along with the challenges in making its integration. Be it in the National Curriculum Framework for School Education which prioritized ICT to be integrated as a subject to study (Government of Nepal [GON], 2005) or in the School Sector Development Program 2016-023 (GON, 2016), ICT integration has been given space as a medium of transforming traditional pedagogical approach. Along with the emphasis, the challenges to the integration have also been narrated. As Rana and Rana (2020) mention, government universities and schools are still waiting for financial assistance so that they can ICT use in education can be adopted. Beside these, socio- economic background of the teachers and students, geographical constraints, and the resistance to changing modality of teaching and learning are frequently recounted as the barriers to ICT use in education.

The constraints, no doubt, are replicated, relating to the pandemic outbreak and bridging gap between educational institutions and students via ICT (Tadeu et al., 2019). Amid this, nevertheless, how the school leaders, teachers, students and parents experience the selfexploration of ICT use seems to have remained pencil- sketched. At the same time, since the challenges to ICT integration amidst COVID- 19 have been regularly popping out of social media, the benefits it can bring as coping mechanism appear to be less contemplated (Tarman, 2020). The study, since aims at exploring how self- learning of ICT encouraged the students, parents, school leaders and teachers grow resilient amidst COVID-19 outbreak, it holds pertinence to unveil how challenges induce self- learning practices, and how ICT can come up as a mechanism 
to bounce back the challenges an individual faces in educational arena when hit by the crisis in the $21^{\text {st }}$ century.

The inspiration to the explore self- learning practices of ICT use among school leaders, teachers, students and parents was contributed by the experiences of shifting from the 'chalktalk' approach in the 2000s to the year 2020 which unveiled the possibility of accessing learners via virtual platform. Performing roles as classroom facilitator, and as an individual leading an academic program, the years had blessed the researchers with ample appreciation for their readiness, enthusiasm and determination to practice newer ways for facilitating the learners. The same was the enthusiasm that constantly encouraged the researcher to explore how internet use could make the facilitation even more exciting. Simultaneously, the readiness to manage daily lesson plans and grade sheets using software like words and excel; and probing upon how fascinating introducing evolution of human society would be through the use of animations kept enabling the researchers realize that the use of ICT was not only reinforcing their pedagogical practices. Rather, it was even helpful for the researchers in coping the challenges like time constraint, boredom of learners in monotonous classes, criticisms of being less updated facilitator, and, a teacher whose alternative is to be searched as soon as possible.

The sudden outbreak of COVID 19, provided the researchers with even stronger rationale to explore how self- learning practice of ICT use could be best adopted for growing resilient. With an urge for physical distancing to be made, and with the repeated projections about uncertainty of schools and colleges to resume, the outbreak had come as a halt to the researchers' enthusiasm as well. However, staying idle with hands folded was not the option the researchers saw! Keeping the anxiety aside, the researchers moved forth, probing upon how the learning of ICT use could be best utilized for bringing the learners together. And as soon as a few learners were brought closer, the enthusiasm overpowered the threat of how to cope with the situation. The success encouraged the researchers, not only to persuade the school and university to try bringing the learners together, but even strengthened the motivation to explore how the school leaders, teachers, students and parents assembled the experiences of making self- learning of ICT use amid the pandemic, and how the ICT use helped them grow resilient.

\section{Purpose of the Study}

The study aimed at uncovering the self-learning practices of ICT use by school leaders, teachers, students and parents of Kathmandu Valley for growing resilient amidst COVID-19 outbreak. It has focused on unveiling how the pandemic came as adversity to the school leaders, teachers, students and parents; and how the self- learning practice of ICT use worked as coping mechanism for them.

\section{Research Questions}

The study aimed to unravel the following research questions: 
i. How do the school leaders, teachers, students and parents of Kathmandu Valley narrate their self- learning practices of ICT use?

ii. How do they articulate their ICT use as resilience mechanism amidst the outbreak of COVID- 19 ?

\section{Delimitations of the Study}

The study has been delimited to exploring the stories of school leaders, teachers, students and parents who align to the institutional schools of Kathmandu Valley. The main focus areas of the studies are the self-learning practices of the participants and reinforcement they experienced for growing resilient with the practices of ICT use they learnt. The stories of their self-learning practices are basically concentrated on their experiences amid closure of schools and colleges during the outbreak of COVID- 19 pandemic while their resilience is delimited to bouncing back the insecurities and stress they faced through utilization of ICT use as coping mechanism.

\section{THEORETICAL UNDERPINNINGS}

The following section provides a brief overview of the theoretical implications which are made in the study. Since the study basically focused on learning practices of the school leaders, teachers, students and parents, the use of connectivism as a learning theory has been used. At the same time, the focus of the study was also on exploring how the learning practices of ICT use have enabled the school leaders, teachers, students and parents to grow resilient amid the COVID 19 outbreak. Hence, the study has also made the use of the theory of resilience.

\section{Learning Theory: Connectivism}

Learning theories as the part of human psychology, in the words of Melchova and Malcik (2012) were developed during the time when learning had no impact through digital technology. Nonetheless, as Melchova and Malcik (2012) further mention, the digital technology has reorganized the way we live, the way we communicate and even the way we learn. In the similar regard, Herlo (2017) has mentioned that living in the age when we are surrounded, and even immersed in technological changes, educational institutions including the universities have to find ways of learning more penetrable and unsolidified paths toward open source and studentcentered learning (Kamenetz, 2010). The same notion of moving towards a more open source of learning connotes to the theory of connectivism as a learning theory for the digital age which states that knowledge exists in the world rather than in the head of the individual (Melchova \& Malcik, 2012). As proposed by Siemans and Downes (2009) cited in Duke, Harper and Johnston (2013), connectivism can also be described as the process of social learning that is networked. The very notion was relatable to the study since the experiences of the participants who were selected had also experienced learning ICT tools, techniques and practices by exploring the world where they had been living and the challenges they had experienced in the world that they had found to have been regulated by ICT. At the same time, as the contribution of ICT use 
as mechanism for bringing about the changes the school leaders, teachers, students and parents desired was also covered by the study, the theory was of a great help.

\section{Resilience Theory}

With its main focus on the capacity of an individual to face adversities, overcome them and even stand stronger amid such situations, the theory of resilience is considered to have emerged, getting associated with an increased emphasis on strengths (Rak \& Patterson, 1996). The strength which Rak and Patterson (1996) have used, is connoted to the ability of an individual to cope with serious adversities or risks which allows him/ her to come out with relatively better outcomes than that of other individuals who might be facing adversities of the similar kind (Rutter, 2013). Rutter's articulation provides an indication that all individuals might not be able to cope with the situation that appears distressing; while only those who are able to cope with the challenges are able to come out with desired positive outcomes. The concept of resilience, to some extent, even reflects Darwin's metaphysics of 'The Survival of the fittest', which, as reviewed by Paul (1988) hints that only those who could struggle with their environment would have best chances of surviving, and procreating their kind while those who would not be able to do so would be rigidly destroyed. Despite having similarity in term of the discussion about the ability to struggle and survive, the theory of resilience differs in a way that it focuses basically on the vulnerabilities one goes through and the competency the individual displays in utilization of promotive measures (Masten \& Powell as cited in Rutter, 2012) so as to come out of the vulnerabilities and stand strongly. The theory was applicable in the study, since it could be helpful for making sense about how the school leader, teacher, student, and parent have coped with the vulnerabilities that they came across being hit by the COVID- 19 and how they stood stronger than others.

\section{ICT in Education and the Context of Nepal: An Introduction}

Integration of ICT in education, for a long period of time, has been a discourse given a great priority in Nepal. Inspired by Education for All (EFA), 'Introduction of information technologybased education at the basic and primary level' was incorporated as one of the major actions in the Long-term Strategies (2012-15) by the Government of Nepal (2003). This initiative hints the readiness showed by the nation to embrace use of ICT integration with the dawn of $21^{\text {st }}$ century. Moving further, the strategies were identified to ensure equitable access to education in Nepal through IT policy (2010), National ICT Policy 2015, SSRP (2009-2015), SSDP 2016-2023- and Three-Year Plan (2011-2013). Apart from this, the National Curriculum Framework (NCF, 2007) has also highlighted the 'Need of ICT based education' (GON, 2007).

Despite the initiatives that are made by the government for introduction and integration of ICT in education, different challenges are reported simultaneously. Some of the challenges that are repeatedly recounted include geographical constraints, lack of adequate infrastructures, awareness and attitude of people towards ICT, poor economic status of parents 
and lack of trained facilitators (Dahal \& Dahal, 2015). Apart from these challenges, as stated by Joshi (2017), provision of computer education as elective subject, lack of ICT related facilities in educational institutions, lack of awareness among the teachers and responsible bodies about ICT practices are considered as the barriers to proper use of ICT in education in Nepalese context.

Challenging though the ICT introduction is considered to be, the opportunities its use can bring are undeniable. As mentioned by the United Nations Educational, Scientific and Cultural Organization (UNESCO) (2014), ICT in education can have multiple opportunities including the orientation of students to new set of skills, access to the students with no or less access to educational institutions, improvement of teachers' proficiency, and the minimization of costs related to traditional approach of instruction. Moreover, as Dhital (2018) illustrates, ICTs can be helpful in assisting teachers to access a wider range of pedagogy which ultimately leads to learning effectiveness of students. At the same time, echoing in the words of Dhital, learning and using ICTs can even benefit teachers to get oriented with administrative tasks and result in complementation, enrichment and transformation of education for better. If the articulations are taken into account, they indicate greater possibility of bringing transformation in education through the use of ICT. At the same time, the literatures even provide a space to probe upon how the challenges that appear in educational landscape in the $21^{\text {st }}$ century can better be resolved through the learning and practice of ICT. However, when it comes to exploring the facets of ICT in education, a greater emphasis is mostly given to what challenges do exist in integrating ICTs in general rather than to how different individuals have been perceiving the use of ICT in their lives.

\section{A Growing Emphasis to ICT Use and Its Integration amid COVID-19}

The sudden outbreak of COVID 19 is reported to have led different dimensions of social life to a halt, where education is no exception. Illustrating the disruption resulted by the outbreak in education, the United Nations Educational, Scientific and Cultural Organization (UNESCO) (2020) counted about 290.5 million students from across the globe to have been hit by school closures and even anticipated that the prolonged closures might threaten the children's right to education. Narrowing down to the context of Nepal, the impact of the COVID outbreak has been apparent in a series of discourses on students' growing intimidation amidst the closures of schools and colleges, and the confusions about their future led by the postponement of standardized tests and exams (Pokharel, 2020 April 25). Vulnerable though the educational landmark seemed to be, practices were initiated by the government, schools, colleges and universities so that the impact of the outbreak on education could be minimized. And, one of the initiatives made for coping with the vulnerabilities has been the adoption of ICT integrated teaching learning.

Looking around ourselves, we can see that ICT integration in teaching learning has become a global discourse at present. Articulated in different ways; be as remote learning or 
virtual or distance learning, ICT has been adopted across the world as a bridge to connect the educational institutions and students who are confined inside their homes. In fact, as Ali (2020) has illustrated, efforts are rapidly being made from the national level to utilize technology which has become a reinforcement to the quick emergence and evolution of remote learning and distance education during the pandemic. The growing emphasis on the use of ICT in educational discourse reflects even in Mulenga and Marban (2020) where they have hinted that shifting into digital pedagogical approach could be a positive response to the COVID- 19 closure. Adopting ICT as an adaptive response to the challenges instigated by the pandemic has even been referred to by a collaborative effort of Harvard Graduate School of Education, the Organization for Economic Cooperation and Development (OECD) and the World Bank where the digital sources including radio, television and internet devices are included in curative module to support the continuity of teaching learning with educational leaders across the globe (Organization for Economic Cooperation and Development [OECD], 2020).

Apart from the initiatives mentioned above, an education cluster contingency plan was disclosed with an initiation of the GON in March 2020 where the main focus was on bridging the gap between schools and home; while the mechanism that was chosen as the bridge was the ICT. As the cluster mentions, the federal government, provincial and local governments were expected to collaborate so that the learning needs of the students from different socioeconomic backgrounds could be catered by through online learning portal, offline learning materials sms-based learning packages, automated voice messages, TV and radio programs, along with the printed materials (Nepal Education Cluster [NEC], 2020) which demanded the use of ICT tools and techniques to a maximum. As the plan itself suggested, ICT has been emphasized amidst the pandemic as a mechanism to grow contingent. In the similar way, collaborative effort was exhibited by UNICEF and Save the Children in preparing and prepositioning of resources like internet, radio and TV as preparedness intervention to prevent 7.2 million school children of Nepal being permanently encumbered from their access to education (United Nations Nepal [UMN], 2020). The preparations and the inclusion of ICT in them make it apparent that adopting ICT at present has been prioritized more as a way to fight back the challenges that have appeared due to the school closures.

\section{Vulnerabilities Articulated within The Alignment: A Metaphor to The Pencil Sketched Opportunities in ICT}

Apart from the initiatives made from the end of the government, different schools, colleges and universities are informed to have showed their readiness in shifting to virtual mode of teaching learning as soon as the prolonged closures were projected. As reported by The Rising Nepal (2020 March 20), no sooner the government announced the closure, Kathmandu, the city commonly acknowledged as a hub of education witnessed the outflow of more than 300,000 individuals in three days. The out flux undoubtedly led to the scattering of the students all 
across the nation, and the only way the schools and colleges saw to reach the students was the embracing of ICT. In the same context, Khati and Bhatta (2020) have articulated that online education was adopted as alternative to face- to- face approach and later formalized by many universities. Amidst this shift, nonetheless, a number of challenges are articulated to have existed. Some of the challenges, in the words of Bhusal and Rimal (2020) include the possibilities of cybercrimes, geographical constraints, discourse of affordability and diverse socio- economic background of the students. Aterya and Jenash (2020) in the similar way, have articulated how lack of private environment, interruptions of electricity due to environmental conditions, and less possibility to conduct hand on practical sessions have been inducing the challenges to remote teaching learning. These articulation, to a great extent, indicate the priority given by studies towards exploring the adversities and vulnerabilities faced by students and educators in embracing ICT in pedagogical practices.

Apart from the vulnerabilities that are explored from the part of students and teachers, studies have even unveiled how the adoption of ICT practices came up with different adversities in the part of the parents. With the decision of the Government of Nepal to introduce digital learning system to continue teaching- learning, parents are stated to have been burdened with the load of school fees and online fees (Poudel \& Subedi, 2020). Poudel and Subedi further stress that the shift to digital approach and the priority given to blending ICT of different forms have particularly been stressful to the families with less access to the resources. And if the remarks about ICT use that have been emerging from different nooks and corners of the country are to be revisited, the challenges that are narrated with relation to the access and practicability of ICT based classes appear to be pretty obvious. At the same time, since the discourse of education and educating itself has been brought up in the long-held tradition of face to face tutoring by the guru (teacher) (Pangeni, 2016), using devices and shifting to a mediated mode of teaching learning might have appeared cumbersome. Despite the challenges that are often related with embracing ICT in education, the way ICT use has been emphasized as a mechanism to fill the gap during the pandemic allows probing upon the stories of the school leaders, teachers, students and parents on how the pandemic induced their aptitude to explore ICT tools and techniques, and how their self- learning practices enabled them grow resilient which have remained behind the curtain.

Indispensability of ICT in the $21^{\text {st }}$ century education (Pineida, 2011) has always been a much-raised discourse in academia. Be it for reducing mass literacy through introduction of distance mode of teaching learning, or for improving pedagogical practices through effective learning, and quality evaluation (Patel, 2017), integration of ICT has been gaining an extensive attention of individuals across globe, and particularly in the country like ours. Beside this, the use of ICT in education has also been linked to enhancing leadership, evident to which is Twining's (2008) argument that the leadership functions can be best achieved when the vision to enhance teaching learning is aligned to the use of ICT. In the similar way, Twining et al. (2013) have projected ICT as an opportunity for supporting change in the educational system that is 
felt required for teachers' professional development. Coming precisely to the present scenario where the pandemic has hit the regular educational phenomenon and change in modality of leading the educational institutions is expected everywhere, initiating, promoting and implementing ICT can facilitate transformational change in school leadership practices (Afshari et al., 2008). The possibility of changing leadership practices in the present scenario that is considered to get easy with integration of ICT encourages developing an understanding that the more the individual is keen at learning and practicing ICT tools and techniques, the less he/she bears the burden of remaining isolated and distressed, no matter how challenging the changing scenario appears to him/ her.

\section{METHODS}

The study has been conducted, being guided by the philosophical paradigm of interpretivism, which believes that the experiences of one individual regarding seeing the adversities and coping them vary. Since vulnerabilities themselves are considered to be relative discourse, and since the way the people experience them form the reality (Levers, 2013) for them, subjective way of experiencing (Guba \& Lincoln, 2005) the vulnerabilities and the subjective response to them made by the research participants have given shape to their ontology that adversities amidst the COVID 19, the use of ICT as coping mechanism, and being resilient are the knowledge that are created by the individual's mind (Rodriguez- Pereyera, 2002) and are relative to the context where they are living.

As the method of the study, narrative inquiry was adopted (Cohen \& Morrison, 2012) so that the experiences of the school leaders, teachers, students and parents regarding their development as resilient beings through the use of ICT could be explored. The school leader, teacher, student and parent who were selected for the study belonged to Kathmandu Valley while purposive sampling was used for selection of participants. This was done since the individuals having knowledge and experience of ICT use and resilience (Creswell \& Clark, 2011) were required for the study. Further, the experiences of the participants were assembled through story telling. In the process of collecting the participants' stories, the researchers engaged with the participants for a prolonged period of time through conversational action, reaction and interaction (Saldana, 2015). While having interaction with the research participants, nonetheless, the researchers even kept reflecting upon the experience of learning ICT use and coping with the vulnerabilities they came across amidst COVID- 19 outbreak.

The narratives that were collected were later transcribed, coded and categorized. Based on the commonality the participants' stories had, the themes were further developed and the meaning was generated, relating the stories with theory and relevant literature. In the process of meaning making, the notions of narrative inquiry- temporality, sociality and place (Clandinin \& Connelly, 2000) were followed so as to maintain the quality of the study as that of an interpretive research. The quality standard was even reinforced by the ethical considerations of 
being tolerant and responsive (Josselson, 2007) which was taken into account while collecting data. At the same time, the researchers have paid respect to their experiences, following the notion of human dignity and values of the research participants (Luban, 2009). Furthermore, strong rapport with the research participants was built during the research process, leading to the generation of meaningful and credible data.

\section{RESULTS}

The section unveils the stories of the research participants, who experienced adversities of different kinds amidst the COVID- 19 outbreak while playing their roles as school leaders, teachers, students and parents; but at the same time, were able to cope the challenges and stand firmly as resilient through their self- learning of ICT use. Meanings about the participants' experiences have been presented under different metaphorical themes.

\section{The COVID- 19 Outbreak: An Avalanche}

The outbreak of COVID - 19 was recounted as an unexpected whirlwind by the research participants, while the waves they experienced were that of fear, anxiety and risk. The wave as a metaphor was articulated by Dipasana, a school leader of Kathmandu Valley with such a meticulousness that it even instigated reflecting upon the researchers' experiences of staying inside the premises, pondering if the identity as facilitators would continue or not. While Dipasana had been recollecting her experience of staying awake for nights during the initial weeks of the pandemic outbreak, the tears in her eyes were telling the vulnerabilities she had gone through, even clearer than her words. With a great sigh, she quoted:

For about three weeks after the announcement of the pandemic outbreak, I kept remaining captivated by the threat of what next! For me, the pandemic meant no school; and no school directly denoted to me that my identity as a school leader was about to get extinct. I could anticipate my school moving towards complete degeneration. I got insomniac, since the regular functions of the school were halted. There were my friends too, who used to share similar feelings of threat and anxiety with me. But I could not stop myself from thinking that I was really vulnerable. There was no communication with the teachers, parents and students and I was feeling like being in isolation, finding no way to lead my career as a school leader! (Dipasana, Personal Communciation, 2020, July 29)

Sumnima's adversities were similar to that of Dipasana. Similar to Dipasana who had been imprisoned in fear of losing existence as a school leader, Sumnima, a school teacher working in a reputed school of Kathmandu had the same feeling of whether she'd be standing as a teacher in the days to come or not! The vulnerability she had gone through reflected very clearly in her surging accent while talking about the days she had gone through.

I say, it was the first time when I asked myself why I chose to be a teacher. There were no schools, and being a teacher without classrooms was appearing impossible to me! I just kept thinking how to retain my existence as a teacher and this thought even 
instigated me to get more irritated, less responsive and restless. Financial break down was adding to my trauma! But I could do nothing, since the school would not pay a teacher who was doing nothing for the school and the students! (Sumnima, Personal Communication, 2020, July 28)

Bhumi's experience as a parent of two children was a little different from that of Dipasana and Sumnima since she had to think a lot on how to remain an encouraging and a strong mother, who would remain less affected by the outbreak of COVID 19. Vulnerable she was herself, however, greater adversity for her was to manage the fear and anxiety her children had been going through amid the school closure.

The outbreak was really challenging. I was feeling traumatized with regular discussions about the uncertainty of the schools to function. But the greater risk for me was the vulnerability of my children who are the school students. I was engrossed by the fear that if I fail to support my children as a strong mother, I won't be standing as firmly as I used to stand in front of them. (Bhumi, Personal Communication, 2020 July 29)

Bidhya, a student pursuing her bachelor's degree in a reputed college of Lalitpur, on the other hand, recounted the risk she faced regarding her academic career. The challenges the pandemic brought to her, however, were no lesser than that of the challenges that were faced by Dipasana, Sumnima and Bhumi.

The college announced its closure overnight! I was puzzled, thinking, 'what about my end semester assessment?' All of us were confined and whenever l'd talk with my friends, the only discourse would be the anxiety. Anxious I had been, since it seemed as if my dream of pursuing BIT was breaking down. I didn't express what my real pain was, but my mom would often talk of my changing behavior! The outbreak was really traumatic. Even today, I get terrible goosebumps, recounting how I had nearly got sick, thinking on how to move on with my academics! (Bidhya, Personal Communcication, 2020, July 28)

From the above- mentioned stories of Dipansana, Sumnima, Bhumi and Bidhya, it could be derived that the vulnerabilities were shared as common experience. Anxiety regarding how to protect the self was experienced by all the participants. However, the derivation of anxiety was made by Dipansana, Sumnima, Bhumi and Bidhya in different way. Different though the pathway to derivation of the knowledge of adversity was, the knowledge they shared about vulnerabilities encouraged the researchers construct the ontology that COVID 19 has really come with vulnerabilities and high risk to the educators, parents and students.

\section{Learning and Getting Connected to the ICT Use: A Mechanism to Grow Resilient}

You can't stop the wave,

but you can learn to surf

Jon Kabat- Zinn

While reflecting upon of how the COVID- 19 pandemic abruptly came as an adversity, and how the adversities were recuperated with the self- learning of ICT use, the researchers recalled Jon 
Kabat- Zinn's illustration of the wave and learning to surf. 'Wave' and 'Learning to surf' appeared to the researchers as a metaphor to how one can learn to utilize coping mechanisms even when he/ she is going through serious adversities. Coping the challenges and getting resilient, however, were not the researchers' experience only! The similar experiences were shared by Dipasana, Sumnima, Bhumi and Bidhya as well, who had bounced back the vulnerabilities they faced through their self -learning practices.

Dipasana, the school leader who was very less familiar about ICT use and practices narrated how the pandemic allowed her to explore different ICT tools and techniques because of which she was able to rise from the anxiety and risk of losing her stance as an educational leader. While she had been swerving from the recounting of her vulnerability to her resiliency, her eyes were sparkling. With the same sparkle in her eyes, she articulated:

Difficult was the situation, and I had really got insomniac. However, one night I recalled the story of an ant which survives by fighting with the tide which my mom used to narrate during my school days. And the same story made me realize that I have to come out of the situation. And, the only way which could lead me towards a brighter day was learning of the ICT use. I had no one to give a bigger help, and I was not a technical kind of person. And I must say, the anxiety had not disappeared. However, keeping the anxiety in one corner of the heart, I went on, exploring how I could communicate with my parents, teachers, and students and how the educational activities could be conducted. The more I went on learning, the more confident I started getting. And, look at me these days! I have started suggesting my friends to find similar mechanisms so that they can also come out of their stress and run their schools' activities virtually. (Dipasana, Personal Communication, 2020, July 29)

Dipasana's hands had been moving on the computer while she had been narrating her story. And the confidence with which she illustrated how her works are appreciated by the parents and the students hinted her resilience. Dipasana's story, at the same time, took the researchers back to the confidence that was gained with self- learning of ICT use. The story simultaneously encouraged relating to the experience of Sumnima as well who had found selflearning of ICT tools as the strategy to grow resilient.

Engrossed in my own melancholy, I had been surfing the google to see if I could find any opportunities to move abroad. I had really got frustrated due to the school closures, and I had no enthusiasm left to continue with my profession. The surfing didn't notify me about any chances to go abroad. But it came to me as an opportunity since I got a glimpse of how to connect with students via zoom application (an ICT tool). I tried doing as shown in the internet. And it was magical! It worked beautifully! Encouraged, I started learning newer techniques and tools, executed them in the class. Now, I was no more an idle teacher. My self- learning enabled me to come out of the risk I had anticipated of losing my career and I can say that I have strongly survived a reversing tide! (Sumnima, Personal Communication, 2020, July 28) 
Dipasana's and Sumnima's story were quite relatable to Bhumi's resilience which started getting mirrored in her body language. Her readiness to explore the prior- knowledge she had about ICT use, as she said, helped her instill confidence in her children that school closure was not the ultimate full stop to getting connected with school and learning.

No sooner my anxiety had started dominating my thoughts, I decided to recall the knowledge about ICT use I had assembled during my university days. I admit, I was going close to emotional devastation with repeated questions of my children about their studies. But as I started learning different ways of engaging my children through ICT tools and techniques, I was able to regenerate the happiness they would express at the completion of their project works. It even encouraged me to stand as a stronger mother who can stand strongly and support her children as an educational leader even when the situation is really against her! (Bhumi, Personal Communication, 2020 July 29)

Bidhya also had the similar experience of rising from the adversities. Her self- learning of ICT use, as she narrated, not only enabled her in getting acquainted with her course content, but even helped her expand her social networking. She could defeat her anxiety regarding her academic career since the exploration allowed her to take extra academic courses during the lockdown and even let her entrepreneurial skill spring.

Just thinking about how to secure my academic career amidst insecurities, I had really been vulnerable. I used to get nightmares about my ruining future. But one day, I talked to my teacher and she suggested me to gather courage. Her words motivated me, and something that really helped me come out of the trauma was my continuous learning of how ICT could be best utilized for developing an academic network. I learnt about different applications through YouTube, and tried manifesting them in newer ways. I even went on exploring how learning applications could be developed and how they could be installed even in simple kind of smart phones. The exploration helped me in a multiple ways. Firstly, I could beat my own fear about my future. Secondly, I could even start my own application as a job from which I have even been able to make some money. I feel like my learning has emancipated me. (Bidhya, Personal Communication, 2020, July 28)

The experiences which the research participants shared reflected the commonality that they all have stood as resilient individuals, coping the adversities that had made them really vulnerable. The mechanism that they applied for beating the vulnerabilities was self- learning of ICT use. Their stories even enabled construction of knowledge that beginning from the self is the best way to bounce back every hard times, while ICT use can come up as strong mechanism to fight against challenges in the present scenario. 


\section{DISCUSSION}

Its undeniable, pandemics hit the mankind in less contemplated way, and are potential of leaving undesired effects. The belief has got even stronger with the outbreak of COVID- 19 that was unexpected, and instigated the collection of distressing experiences. Similar experience of distress, anxiety and fear was assembled during the COVID 19 pandemic by the participants of the study too, which has made the researchers believe that pandemics can result to heightened level of anxiety experience (Roy et al., 2020). The effect of COVID 19 in the form of anxiety and vulnerability has been reviewed by Ozdin and Ozdin (2020) as well, who articulate how traumatic the pandemic can be; and how the questions about its uncertain existence can reduce people's sense of security. The concern about the reduction in sense of security and uncertainty reflected in the stories of Dipasana, Sumnima, Bhumi and Bidhya as well. The insecurity that the participants faced, however, were more associated with school closure which has been enacted so as to maintain social distancing and self- isolation (Jordan, 2020 as cited Mustafa, 2020) for combating the spread of the corona virus. Similar to The National Child Traumatic Stress Network (2020) which discusses the adversities faced by the school system for connecting, teaching and supporting students and families due to the uncertainties of the COVID- 19 pandemic, concern about how to approach the students and families, and how to continue the school functions had created adversities for Dipasana and Sumnima as well.

Similar to the adversities faced by the school leaders and teachers on how to connect to the families and retain their stance in the domain of educational leadership, uncertainties of the pandemic had been stressful for Bidhya, a student as well. The anxiety she expressed spoke very well of how confused and lost she had been feeling, and how the confusion had been leading her to frustration and anxiety (UNICEF, 2020) amidst the closure resulted due to COVID19 outbreak. The growing anxiety among the students due to school closures echoes in (Rehman et al., 2020) as well which presents that the students all over the world are experiencing distress due to uncertainty of examinations and with regards to the availability of job in the days to come. Parents on the other hand, as narrated by Bhumi were reported to have gone through the challenges resulted due the anxiety seen in their children (UNICEF, 2020) and the growing probability of the children falling back in their academic growth amid prolonged school closure (Kuhfeld \& Tarasawa, 2020).

Success is not final,

Failure is not fatal:

It is the courage to continue that counts!

\section{Winston Churchill}

The adversities faced by the participants of this study were stressful. But, as Winston Churchill has mentioned, Dipasana, Sumnima, Bhumi and Bidhya didn't give up. Rather, they rose from the adversities and were able to stand through self- exploration and learning of the ICT use. The same competency the research participants displayed in learning ICT has 
stimulated the researchers' belief that being resilient individual is not about gaining success magically; rather it is all about how the people can adapt in the environment where they are living, making right use of the available resources (Rutter, 2006 as cited in Shean, 2015) to bounce back the vulnerabilities they come across. The resources which Rutter (2006) has mentioned for growing resilient, in the stories of the participants of this study, were the ICT tools and techniques, while the use of ICT was reinforced by their self- learning practices. The stories of Dipasana, Sumnima, Bhumi and Bidhya illustrated that they were guided by the conviction that learning in the digital age could be facilitated by being a part of network that constitutes humans and non- humans (Bell, 2009). As the theory of connectivism further introduces learning as a cyclical process where the learners connect to the network for generating information (Kop \& Adrian, 2008), the research participants had also been able to construct newer information through their connection with ICT network. At the same time, Dipasana, Sumnima, Bhumi and Bidhya were even successful in connecting to the community who aligned with them with regard to their interest in continuity of educational functions through interaction, sharing, and dialoguing (Siemens, 2004), which ultimately helped them in the fighting back the stress and anxiety and rise as resilient individuals.

The closure of schools during COVID 19 had induced Sumnima, a school teacher's stress in such a way that she had started perceiving her teaching profession to be strenuous and frustrating (Lambert, O'Donnell, Kusherman \& McCarthy, 2006). School closure during the outbreak, in the similar way had instigated Dipasana as well to question her own choice of being a school leader. Nonetheless, both the individuals made the utilization of self-learning of ICT use as coping strategy which helped them mediate the level of stress (Montogomery \& Rupp, 2005). Similar to Dipasana and Sumnima, the stories narrated by Bhumi and Bidhya also illustrated that their readiness and the positivity (Lopez \& Snyder, 2011) they carried that they could learn better use of ICT during the COVID 19, not only developed their competency in the ICT use, but also helped them adapt positively (Eldridge, n.d.) amidst vulnerabilities they had been experiencing due to school and college closure. Furthermore, the resilience the research participants had developed through their self- learning of ICT use even boosted their confidence that they could bounce back the challenges of similar kind in the days to come. It has provided the researchers with an insight that learning the ICT use in the $21^{\text {st }}$ century can come out as a strong mechanism to cope the vulnerabilities the teachers, parents, educational leaders and students come across in the educational process.

\section{CONCLUSIONS AND IMPLICATIONS}

The study enabled construction of knowledge that, among the numerous adversities the outbreak of COVID- 19 has brought, the closure of schools and colleges resulted in high degree of stress and insecurity among the school leaders, teachers, students and parents. Vulnerable though the individuals had been feeling, they even carried the positive psychology that they 
could find ways and bounce back the adversities. Hence, the school leaders, teachers, parents and students made self- learning of ICT use which worked as coping mechanism for them. Through the utilization of ICTs, they were not only able to reduce their stress and anxiety, but were also able to come out of the vulnerabilities and stand stronger. At the same time, the resilience they developed with the self- learning of ICT use further ensured them about their potential of bouncing the challenges back in the days to come too.

The study implies that self- learning and the significance of ICT are to be given emphasis in pedagogical domain. Furthermore, it even infers further exploration to be made in educational leadership about how the crises like pandemic can bring insecurities and stress among different stakeholders, and how the insecurities can be bounced back through thoughtful use of ICTs.

\section{REFERENCES}

Afshari, M., Bakar, K. A., Luan, W. S., Samah, B. A., \& Fooi, F. S. (2008). School leadership and information communication technology. The Turkish Online Journal of Education Technology, 7(4), 1- 10.

Ali, W. (2020). Online and remote learning in higher education institutes: A necessity in light of COVID 19 pandemic. Higher Education Studies, 10(3), 16- 25.

Alkahtani, A. (2017). The challenges facing the integration of ICT in teaching in Saudi secondary schools. International Journal of Education and Development Using Information and Communication Technology, 13(1), 32- 51.

Atreya, A., \& Jenash, A. (2020). Distant virtual medical education during COVID- 19: Half a loaf of bread. https://www.doi.org/ 10.1111/tct.13185

Bell, F. (2009). Connectivism: A network theory for teaching and learning in a connected world. University of Salford. https://usir.salford.ac.uk/id/eprint/2569/1/ConnectivismEdDev.pdf

Bhusal, S., \& Rimal, S. (2020). Challenges of online learning in Nepal. https://www.researchgate.net/publication/341930135_Challenges_of_Online_Learnin g_in_Nepal

Calandinin, D. J., \& Connelly, F. M. (2000). Narrative inquiry: Experience and story in qualitative research. Calif Josses- Bass.

Cener, E., Acun, I., \& Demirhan, G. (2015). The impact of ICT on pupil's achievement and attitudes in social studies. Journal of Social Studies Education Research, 6(1), 190- 207.

Creswell, J. W., \& Clark, V. L. P. (2011). Designing and conducting mixed method research. Sage.

Dahal, B., \& Dahal, N. (2015). Opportunities and challenges to use ICT in Nepalese Mathematics classroom. Proceedings of Second National Conference on Mathematics Education, 5052, Pokhara, Nepal. 
Dhital, H. (2018). Opportunities and challenges to use ICT in government school education of Nepal. International Journal of Innovative Research in Computer and Communication Engineering, 6(4), 3215- 3220.

Duke, B., Harper, G., \& Johnston, M. (2013). Connectivism as a digital age learning theory. The International HETL Review (Special Issue), 4- 13. https://www.hetl.org/wpcontent/uploads/2013/09/HETLReview2013SpeciallssueArticle1.pdf

Eldridge, M. (n.d.). Understanding the factors that build teacher resilience (A doctoral dissertation). University of London.

Government of Nepal. (2003). Education for All: National Plan of Action Nepal. https://www.moe.gov.np/assets/uploads/files/EFA_NPA_2001-2015_English.pdf

Government of Nepal. (2007). National Curriculum Framework for School Education in Nepal. https://www.moe.gov.np/assets/uploads/files/National-Curriculum-Framework-2007English.pdf

Government of Nepal. (2009). School Sector Reform Plan 2009-2015. http://www.moe.gov.np/assets/uploads/files/SSRP_English.pdf

Government of Nepal. (2013). ICT in Education Master Plan 2013-2017. https://www.moe.gov.np/assets/uploads/files/ICT_MP_2013_(Final)_.pdf

Government of Nepal. (2016). School Sector Development Plan 2016-2023. http://www.moe.gov.np/assets/uploads/files/MOE_SSDP_Final_Document_Oct_2016. pdf

Government of Nepal. (2005). National Curriculum Framework for School Education (Preprimary-12) in Nepal. https://librarykvpattom.files.wordpress.com/2009/06/ncfnepal.pdf

Joshi, D. R. (2017). Policies, practices and barriers of ICT utilization in school education in Nepal. International Journal of Research in Social Sciences, 7(2), 408- 417.

Josselson, R. (2007). The ethical attitude in narrative research. In D.J. Clandinin (Ed.), Handbook of narrative inquiry: Mapping a methodology (pp. 537-566). Sage Publications.

Kamenetz, A. (2010). DIY U: Edupunks, edupreneurs, and the coming transformation of higher education. Chelsea Green Publishing.

Khati, K., \& Bhatta. K. R. (2020). Challenges of online education during COVID- 19 pandemic in Nepal. International Journal of Entrepreneurship and Economic Issues, 4(1), 45- 49.

Kuhfeld, M., \& Tarasawa, B. (2020). The COVID 19 slide: What summer learning loss can tell us about the potential impact of school closure on student academic achievement. Collaborative for Student Growth (pp 1-7). https://www.nwea.org/content/uploads/2020/05/Collaborative-Brief_Covid19-SlideAPR20.pdf

Lambert, R., O’Donnell, M., Kusherman, J., \& McCarthy, C. J. (2006). Teacher stress and classroom structural characteristics in preschool settings. In R. Lambert \& C. McCarthy 
(Eds.), Understanding teacher stress in an age of accountability (pp. 105-120). Information Age.

Levers, M. J. D. (2013). Philosophical paradigms, grounded theory, and perspectives on emergence. Sage Open, 3(3), 1- 6.

Lopez, S. J., \& Snyder, C. R. (Eds.). (2011). The Oxford handbook of positive psychology. https://www.oxfordhandbooks.com/view/10.1093/oxfordhb/9780195187243.001.000 1/oxfordhb-9780195187243

Montgomery, C., \& Rupp, A. A. (2005). Meta-Analysis for Exploring the Diverse Causes and Effects of Stress in Teachers. Canadian Journal of Education, 28(3), 458-486.

Mulenga, E. M., \& Marban, J. M. (2020). Is COVID- 19 the gateway for digital learning in mathematics education? Contemporary Educational Technology, 12(2), 1- 11.

Nepal Education Cluster. (2020). COVID- 19 Education cluster contingency plan, 2020. https://www.doe.gov.np/assets/uploads/files/54ba4942574885a514869a72a6b456cd. pdf

Organization for Economic Cooperation and Development. (2020). Supporting the continuation of teaching and learning during the COVID- 19 pandemic.

https://www.oecd.org/education/Supporting-the-continuation-of-teaching-andlearning-during-the-COVID-19-pandemic.pdf

Ozdin, S., \& Ozdin, S. B. (2020). Levels and predictors of anxiety, depression and health anxiety during COVID- 19 pandemic in Turkish society: The importance of gender. International Journal of Social Psychiatry, 66(5), 1-8.

Pangeni, S. (2016). Open and distance learning: Cultural practices in Nepal. European Journal of Open, Distance and e-Learning, 19(2), 32- 45.

Patel, P. (2017). ICT pedagogy for effective learning, education and quality evaluation. International Journal of Computational and Mathematical Sciences, 6(5), 101- 107.

Paul, D. B. (1988). The selection of the "Survival of the Fittest". Journal of History of Biology, 21(3), 411- 424.

Pineida, F. O. (2011). Competencies for the $21^{\text {st }}$ century: Integrating ICT to life, school and economical development. Procedia-Social and Behavioral Sciences, 28, 54- 57.

Pokharel, K., (2020). Educational implications of COVID- 19. The Rising Nepal. https://risingnepaldaily.com/opinion/educational-implications-of-covid-19

Poudel, K., \& Subedi, P. (2020). Impact of COVID- 19 on socio- economic and mental health aspects in Nepal. International Journal of Social Psychiatry, 1- 8.

Rak, C. F., \& Patterson, L. E. (1996). Promoting resilience in at- risk children. Journal of Counseling \& Development, 74(4), 368- 373.

Rana, K \& Rana, K. (2020). ICT integration in teaching and learning activities in higher education: A case study of Nepal's teacher education. Malaysian Online Journal of Educational Technology, 8(1), 36- 47. 
Ratheeswari, K. (2018). Information communication technology in education. Journal of Applied and Advanced Research, 3(1), 45- 47.

Rehman, U., Shahnawaz, M. G., Khan, N. H., Kharshiing, K. D., Khursheed, M., .... \& Uniyal, R. (2020). Depression, anxiety and stress among Indians in times of COVID- 19 lockdown. Community Mental Health Journal, 1- 7. https://www.doi.org/10.1007/s10597-02000664-x

Rodriguez- Pereyara, G. (2002). Resemblance nominalism: A solution to the problem of Universals. Oxford University Press.

Roy, D., Tripathy, S., Kar, S. K., Sharma, N., Verma, S. K., \& Kaushal, V. (2020). Study of knowledge, attitude, anxiety \& perceived mental healthcare need in Indian population during COVID- 19 pandemic. Asian Journal of Psychiatry, 51. https:www.doi.org/10.1016/j.ajp.2020.102083.

Rutter, M. (2012). Resilience as a dynamic concept. Development and Psychopathology, 24 (2012), 335- 344.

https://pdfs.semanticscholar.org/e09f/40f24084a82d775eba9e211dc4a988fcab0d.pdf

Rutter, M. (2013). Annual research review: Resilience- clinical implications. The Journal of Child Psychology and Psychiatry, 54, 474- 487.

Saldana, J. (2015). Thinking qualitatively: Methods of mind. Sage.

Salmon, G. (2004). E- Moderating: The key to teaching and learning online. Routledge Falmer.

Shean, M. (2015). Current theories relating to resilience and young people: A literature review. Victorian Health Promotion Foundation.

Tadeu, P., Fernandez Batanero, J., \& Tarman, B. (2019). ICT in a Global World. Research in Social Sciences and Technology, 4(2), i-ii. https://doi.org/10.46303/ressat.04.02.ed

The National Child Traumatic Stress Network. (2020). Trauma- informed school strategies during COVID- 19. https://www.nctsn.org/resources/trauma-informed-schoolstrategies-during-covid-19

The Rising Nepal. (2020). People leaving Kathmandu on the rise. The Rising Nepal. https://risingnepaldaily.com/mustread/people-leaving-kathmandu-on-the-rise-photofeature

Twining, P. (2008). Framing IT use to enhance educational impact on school- wide basis. In J. Voogt \& G. Knezek (Eds.), International Handbook of Information Technology in Primary and Secondary Education (pp 555- 577). Springer.

Twining, P., Raffaghelli, J.E., Albion, P. R., \& Knezek, D. (2013). Moving education into the digital age: The contribution of teachers' professional development. Journal of Computer Assisted Learning, 29(5), 426- 437.

United Nations International Children's Emergency Fund. (2020). Psychological support for children during COVID-19: A manual for parents and caregivers. https://www.unicef.org/india/media/3401/file/PSS-COVID19-Manual-ChildLine.pdf 
United Nations Educational, Scientific and Cultural Organization. (2020). 290 millions students out of school due to COVID-19: UNESCO releases first global numbers and mobilizes response. https://en.unesco.org/news/290-million-students-out-school-due-covid-19unesco-releases-first-global-numbers-and-mobilizes

United Nations Nepal. (2020). COVID- 19 Nepal: Preparedness and response plan (NPRP). https://www.who.int/docs/default-source/nepal-documents/novel-coronavirus/covid19-nepal-preparedness-and-response-plan-(nprp)-draft-april-9.pdf?sfvrsn=808a970a_2

Waters, S., \& Hensley, M. (2020). Measuring rural P-12 teachers' attitudes, perceptions, and utilizations of social media. Research in Social Science and Technology, 5(3), 25- 54. https://ressat.org/index.php/ressat/article/view/506/90 